\title{
Analysis of Ammonia Toxicity in Landfill Leachates
}

\author{
Takuya Osada, ${ }^{1}$ Keisuke Nemoto, ${ }^{1}$ Hiroki Nakanishi, ${ }^{1}$ Ayumi Hatano, ${ }^{1}$ Ryo Shoji, ${ }^{1}$ \\ Tomohiro Naruoka, ${ }^{2}$ and Masato Yamada ${ }^{2}$
}

\author{
${ }^{1}$ Department of Chemical Science and Engineering, Tokyo National College of Technology, 1220-2 Kunugida-Machi, \\ Hachioji, Tokyo 193-0997, Japan \\ ${ }^{2}$ Research Center for Material Cycles and Waste Management, National Institute for Environmental Studies, \\ Onogawa 16-2, Tsukuba, Ibaraki 305-8506, Japan
}

Correspondence should be addressed to Ryo Shoji, shoji@tokyo-ct.ac.jp

Received 23 May 2011; Accepted 6 July 2011

Academic Editor: A. H. Milton

Copyright () 2011 Takuya Osada et al. This is an open access article distributed under the Creative Commons Attribution License, which permits unrestricted use, distribution, and reproduction in any medium, provided the original work is properly cited.

Toxicity identification evaluation (TIE) phase I manipulations and toxicity test with D. magna were conducted on leachates from an industrial waste landfill site in Japan. Physicochemical analysis detected heavy metals at concentrations insufficient to account for the observed acute toxicity. The graduated $\mathrm{pH}$ and aeration manipulations identified the prominent toxicity of ammonia. Based on joint toxicity with additive effects of unionized ammonia and ammonium ions, the unionized ammonia toxicity $\left(\mathrm{LC}_{50, \mathrm{NH}_{3}(\mathrm{aq})}\right)$ was calculated as $3.3 \mathrm{ppm}$, and the toxicity of ammonium ions $\left(\mathrm{LC}_{50, \mathrm{NH}_{4}}{ }\right)$ was calculated as $222 \mathrm{ppm}$. Then, the contribution of ammonia toxicity in the landfill leachate toxicity was calculated as $58.7 \mathrm{vol} \%$ of the total toxicity in the landfill leachate. Other specific toxicants masked by ammonia's toxicity were detected. Contribution rate of the toxicants other than by ammonia was $41.3 \mathrm{vol} \%$ of the total toxicity of the landfill leachate.

\section{Introduction}

Landfill leachates are highly polluted effluents [1]. The leachate has to be treated in a downstream waste water treatment plant, and it is necessary to identify toxicity causative chemicals for the effective treatment. Accordingly, methods were developed to assist in identifying effluent toxicants, and these methods are well known as a toxicity identification evaluation, TIE. TIE methods have been proven to be effective tools for characterizing and identifying toxicants in samples of effluents and other complex mixtures [2]. Two types of TIE, treatability-based TIE and chemical-specific TIE, have been studied so far. Treatability-based TIE is a general approach in TIE to determine the effective water treatments and (if possible) thereby speculate the toxicity-controlling chemical(s). Chemical-specific TIE was developed to evaluate the toxicity-contributed chemicals more simply. The approach is to compare chemical analysis data with concentration of chemicals to express toxicity (e.g., $\mathrm{LC}_{50}, \mathrm{EC}_{50}$ (the lethal or effective concentration for $50 \%$ of test organisms), etc.). However, these TIEs have some problems. First, in the treatability-based TIE, when the chemical which highly contributed to the toxicity was included in the sample, the toxicity of other chemical cannot be detected by the TIE based on a single toxicity test. Second, in the chemicalspecific TIE, when concentration of many chemicals were higher than $\mathrm{LC}_{50}$ or $\mathrm{EC}_{50}$, toxicity causative chemicals for effective treatment cannot be identified. Third, environmental factor (e.g., $\mathrm{pH}$ ) cannot be considered. Ionized and unionized forms of the compounds such as heavy metals have different toxicity to the organisms. The ionizable compounds are commonly found in landfill leachate including ammonia and some organic compounds as well as heavy metals. In addition, $\mathrm{pH}$ affects metal toxicity through changes in solubility and speciation $[3,4]$. Contribution rate is one of the quantitative approaches to solve the above-mentioned problems. The contributions of each component were calculated as quotients of concentration, though contribution rate has not been used for identification of toxicity-causative chemicals. Therefore, contribution rate approach for identification of toxicity causative chemicals can consider the effect of $\mathrm{pH}$ in landfill leachate toxicity for more effective treatment.

This manuscript describes toxicity testing and TIE studies conducted on industrial waste landfill leachate. Through 
this case study, we describe the problems of TIE testing used to characterize, identify, and confirm ammonia as the cause of acute toxicity to the Daphnia magna. Ammonia toxicity considering $\mathrm{pH}$ in the landfill leachate was analyzed. The objectives of this study are to perform contribution rate approach for identification of toxicity causative chemicals considering the effect of ammonia toxicity changing by $\mathrm{pH}$, and to detect toxicity causative chemicals other than ammonia with the contribution rate approach.

\section{Materials and Methods}

2.1. Effluent Sampling and Chemical Analysis of Landfill Leachate. Two effluents were collected from the same landfill site in Japan in 2008 and 2009. The landfill site for final disposal of industrial wastes has already been closed since the 1990s. Metal concentrations were determined with an ICP-AES (SII SPS7800) in landfill leachate in 2008, and an ICP-MS (Agilent 7500s, YOKOGAWA) in landfill leachate in 2009. The ammonium ions and other ionic chemical parameters $\left(\mathrm{F}^{-}, \mathrm{Cl}^{-}, \mathrm{NO}_{2}^{-}, \mathrm{Br}^{-}, \mathrm{SO}_{4}^{2-}, \mathrm{Na}^{+}, \mathrm{K}^{+}, \mathrm{Mg}^{2+}\right.$, and $\mathrm{Ca}^{2+}$ ) concentrations were determined by using an ionic chromatograph (TOSOH IC-2001). Total organic carbon concentration (TOC) was also analyzed by using a TOC analyzer (TOC-5000A, Shimadzu). Before these physicochemical analysis, samples were filtered with a $0.45 \mu \mathrm{m}$ paper filter. In ICP-AES, samples were acidified with twentyfold diluted $65 \mathrm{wt} \%$ nitric acid.

2.2. Acute TIE Manipulations. Acute TIE studies began with a full phase I toxicity characterization as described by USEPA [2]. This procedure involves some different tests, which evaluate the effect of physical/chemical manipulations on effluent toxicity. Comparing the toxicity of manipulated samples with that of unmanipulated effluent provides information on the physical/chemical properties of the specific toxicant(s). Baseline effluent toxicity test was conducted at effluent dilutions of 100 vol $\%$, 50 vol $\%$, 25 vol $\%, 12.5$ vol $\%$ and $6.25 \mathrm{vol} \%$. pH adjustment was used throughout phase I to provide more information on nature of the toxicants. Changes in $\mathrm{pH}$ can affect the solubility, polarity, volatility stability, and speciation of a compound, thereby affecting its bioavailability as well as its toxicity. One molar of $\mathrm{NaOH}$ or 1.0 $\mathrm{M} \mathrm{HCl}$ was added dropwise to the samples to control the $\mathrm{pH}$ near 11 or 3 . The aeration test is designed to determine how much effluent toxicity can be attributed to volatile, sublatable, or oxidizable compounds. The $\mathrm{pH}$ of the acidic and basic effluent and dilution water aliquots should be checked every $5 \mathrm{~min}$ during the first $30 \mathrm{~min}$ of aeration and every $10 \mathrm{~min}$ thereafter. If the $\mathrm{pH} 3$ or $\mathrm{pH} 11$ solution drifts more than $0.2 \mathrm{pH}$ units, it must be readjusted back to the nominal value. The graduated test $\mathrm{pH}$ test was also modified by performing the test at $\mathrm{pH} 6.5,7.5$, and 8.5. Since ammonia toxicity significantly varies over this range of $\mathrm{pH}$ values, the relative difference in toxicity could still be examined. EDTA is a strong chelating agent, and its addition to water solution produces relatively nontoxic complexes with many metals. Oxidant reduction test was designed to determine to what extent constitutes reduced by the addition of sodium thiosulfate are responsible for effluent toxicity. Concentration of sodium thiosulfate equal to and lower than the thiosulfate $\mathrm{LC}_{50}$ for test species being used are added to several containers with effluent at the $100 \%$ concentration. In addition to the phase I manipulations described by USEPA, other manipulations were conducted to further characterize the effluent toxicant(s). Filtration manipulations tests were conducted $(\mathrm{MF}=$ microfiltration; pore diameter $0.45 \mu \mathrm{m}, \mathrm{UF}=$ ultrafiltration; membrane area $0.40 \mathrm{~m}^{2}$ pressure $0.40 \mathrm{MPa}$ (RF002040, ADVANTEC MFS, INC. Tokyo, Japan), RO = reverse osmosis; membrane area $0.40 \mathrm{~m}^{2}$ pressure $0.40 \mathrm{MPa}$ (RF000670, ADVANTEC MFS, INC. Tokyo, Japan)).

2.3. Ammonia Toxicity Testing and Analysis. In aqueous solution, un-ionized ammonia $\left(\mathrm{NH}_{3}(\mathrm{aq})\right)$ exists in equilibrium with the ammonium ion $\left(\mathrm{NH}_{4}{ }^{+}\right)$according to the dissociation equation:

$$
\mathrm{NH}_{4}^{+}+\mathrm{H}_{2} \mathrm{O} \stackrel{\mathrm{Ka}}{\longleftrightarrow} \mathrm{NH}_{3}(\mathrm{ap})+\mathrm{H}_{3} \mathrm{O}^{+} \text {. }
$$

Total ammonia concentration is the sum of un-ionized and ionized ammonia. The toxic effect of total ammonia increases with increasing $\mathrm{pH}$, indicating that the un-ionized ammonia is the main toxic form. Un-ionized ammonia concentration was calculated by using ion speciation analysis software MINEQL+ (Environmental Research Software) and ammonium ion concentration measured in this study. To specify the ammonia toxicity, samples with pure ammonium chloride were adjusted in terms of $\mathrm{pH}$ at 7.0 and then the toxicity was tested with D. magna.

D. magna acute test was performed according to OECD guideline 202, at adjustment of $\mathrm{pH}$ using diluted $\mathrm{NaOH}$ or $\mathrm{HCl}$ solution. Test organisms originated from a healthy D. magna clone which has been cultured in the laboratory under standardized conditions in the ISO test solution $(2.00$ $\times 10^{-3} \mathrm{M} \mathrm{CaCl}_{2}, 5.00 \times 10^{-4} \mathrm{M} \mathrm{MgSO}_{4} \cdot 7 \mathrm{H}_{2} \mathrm{O}, 7.70 \times$ $10^{-4} \mathrm{M} \mathrm{NaHCO}_{3}$, and $\left.7.71 \times 10^{-5} \mathrm{M} \mathrm{KCl}\right)$. Acute toxicity was assessed by noting the effects of the test compounds on the effective concentration of D. magna. The tests were conducted at a constant temperature of $20 \pm 1^{\circ} \mathrm{C}$. D. magna were exposed to each landfill leachates, ammonia, and bisphenol A for 48 hour of exposure duration. The number of mortality $D$. magna was recorded. The acute toxicity endpoint was determined as the $\mathrm{LC}_{50}$ of a chemical that causes $50 \%$ of reduction of D. magna survival. The toxicity of the target chemicals have been evaluated as the influence of matrix effects for the determination of $\mathrm{LC}_{50}$ values. The biological response is correlated to the toxicant concentration. The logistic dose response relationship is described as follows [5]:

$$
R=\frac{100}{1+\left(x / x_{50}\right)^{\beta}},
$$

where $R=$ biological response as percentage of the mortality rate of $D$. magna, $x$ was concentration of toxicant, and $x_{50}$ was the concentration of poison that resulting $50 \%$ 
reduction of survival in $D$. magna, $\beta$ is the shape parameter of the dose response curve.

A simple model to describe the toxicity of a protolyzing substance is based on its dissociation and the addition of each form in the dissociation [6]:

$$
\begin{aligned}
\frac{1}{\mathrm{LC}_{50, \text { tot }}}= & \frac{1}{\mathrm{LC}_{50, \mathrm{NH}_{4}{ }^{+}}}-\left(\frac{1}{\mathrm{LC}_{50, \mathrm{NH}_{4}{ }^{+}}}-\frac{1}{\mathrm{LC}_{50, \mathrm{NH}_{4}{ }^{+}(\mathrm{aq})}}\right) \\
& \times \frac{\mathrm{Ka}}{\mathrm{Ka}+\mathrm{C}_{\mathrm{H}^{+}}} .
\end{aligned}
$$

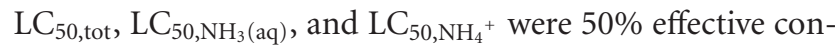
centration expressed as total ammonia, un-ionized ammonia and ammonium ion, respectively, Ka was stability constant for $\mathrm{NH}_{3}$ and $\mathrm{NH}_{4}^{+}, \mathrm{C}_{\mathrm{H}^{+}}$was concentration of hydrogen-ion. From a linear fit with data of the toxic effect as $1 / \mathrm{LC}_{50 \text {,tot }}$ against dissociation expressed as dissociation of ammonium, the toxicity of the un-ionized ammonia is obtained from the intercept, and the toxicity of the ammonium ion is obtained from the slope and the intercept.

2.4. Contribution Rate Calculation. The toxic contribution of the specific toxicants in the landfill leachate was derived by calculations of contribution rate at the $\mathrm{LC}_{50}$ concentration of the leachate $(\% \mathrm{v} / \mathrm{v})$. First, the concentrations of toxicity causative chemicals were measured in the landfill leachate (measured), then the concentrations of the the toxicity causative chemicals in the $\mathrm{LC}_{50}$ mixture (mixture) were calculated. Then, for each toxicity causative chemicals, the mixture was compared with the specific $\mathrm{LC}_{50}$ of each toxicity causative chemicals:

$$
\begin{aligned}
& \frac{\text { Landfill leachate } \mathrm{LC}_{50, \mathrm{NH}_{4}{ }^{+} \text {or } \mathrm{NH}_{3}(\mathrm{aq})}}{\mathrm{LC}_{50, \mathrm{NH}_{4}{ }^{+} \text {or } \mathrm{NH}_{3}(\mathrm{aq})}} \times 100 \\
& =\text { Contribution on rate of } \mathrm{NH}_{4}{ }^{+} \text {or } \mathrm{NH}_{3}(\mathrm{aq}) \text { [vol\%]. }
\end{aligned}
$$

\section{Results and Discussion}

3.1. Landfill Leachate Characterization and Chemical-Specific TIE Approach. Table 1 shows physico-chemical analysis of industrial waste landfill leachate and $\mathrm{LC}_{50}$ values of each chemical components for D. magna. Landfill leachates showed high ammonia concentration and elements of salinity concentration, such as potassium and sodium. Additionally, heavy metal concentrations in both landfill leachate samples were lower than each $\mathrm{LC}_{50}$.

Physico-chemical analysis data with $\mathrm{LC}_{50}$ value in each components were compared for chemical-specific TIE approach, then the results showed that heavy metals were not toxicity causative chemicals. Unfortunately, many kinds of toxicity causative chemicals were derived by the chemicalspecific TIE approach. Another trial on the chemical-specific TIE performed by Shoji et al. provided precious information on the toxicity-controlling chemicals in landfill leachates [7].

\begin{tabular}{|c|c|c|c|}
\hline \multirow{2}{*}{ Chemical } & \multicolumn{2}{|c|}{ Landfill leachate (ppm) } & \multirow{2}{*}{$\begin{array}{c}\mathrm{LC}_{50} \text { of Daphnia } \\
\text { magna } \\
\text { (literature values) } \\
\text { (ppm) }\end{array}$} \\
\hline & 2008 & 2009 & \\
\hline $\mathrm{NO}_{3}^{-}$ & N.D. & N.D. & $3581[16]$ \\
\hline $\mathrm{SO}_{4}{ }^{2-}$ & 17.7 & 2530 & $2560[16]$ \\
\hline $\mathrm{Na}^{+}$ & 1760 & 3130 & $3310[16]$ \\
\hline $\mathrm{NH}_{4}^{+}$ & 334 & 361 & 25.7 \\
\hline $\mathrm{K}+$ & 102 & 380 & $337[16]$ \\
\hline TOC & 147 & 152 & - \\
\hline $\mathrm{Cu}$ & $2.25 \times 10^{-5}$ & $3.48 \times 10^{-2}$ & $5.73 \times 10^{-2}[17]$ \\
\hline $\mathrm{Zn}$ & N.D. & $4.73 \times 10^{-2}$ & $3.34 \times 10^{-1}[18]$ \\
\hline $\mathrm{Ni}$ & N.D. & $5.64 \times 10^{-2}$ & $1.66 \times 10^{-1}[18]$ \\
\hline $\mathrm{Pb}$ & $3.19 \times 10^{-2}$ & $3.70 \times 10^{-2}$ & $4.97[19]$ \\
\hline Bisphenol A & 16.3 & 14.8 & 15.2 \\
\hline $\mathrm{pH}$ & $8.3( \pm 0.3)$ & $7.7( \pm 0.1)$ & - \\
\hline
\end{tabular}
Twenty-five landfill leachate samples were examined by a toxicity test and chemical analyses [7]. By comparing two
TABLE 1: Chemical analysis of waste landfill leachate and LC50.

N.D. $=$ not detected: detection limits of $\mathrm{NO}_{3}{ }^{-}, \mathrm{Zn}$, and $\mathrm{Ni}$ were $0.038 \mathrm{ppm}$, $0.004 \mathrm{ppm}$, and $0.006 \mathrm{ppm}$ ([16] Dowden and Benette 1965. [17] Naddy, et al. 2002. [18] Chapman, et al. 1980. [19] Elten-Unal, et al. 1998.)

important parameters describing dose-response relationship (the $\mathrm{EC}_{50}$ value and the slope) between landfill leachate sample and 255 kinds of chemicals, possible candidates of toxicity-controlling chemical were listed as bisphenol A and other phenols. Subsequently performed chemical analyses successfully showed the presence of such chemicals, and the concentration of these chemicals partly explained the observed toxicity. In order to take an effective countermeasure for the waste landfill leachate, both chemical analyses and toxicity tests can provide important information to find the targeted and cost-effective water treatment.

3.2. Treatability-Based TIE Approach. Figure 1 shows results of acute phase I characterization testing with a $D$. magna immobilization test. The baseline $\mathrm{LC}_{50}$ for $D$. magna was approximately $20 \mathrm{vol} \%$ of the landfill leachate. Toxicity of solid phase extraction-treated leachate and EDTA-addition leachate were not reduced compared to that of untreated leachate. Aeration manipulation tests showed a clear decrease in toxicity. The acutely toxic landfill leachate was submitted for chemical analysis shown in Figure 1; ammonia was detected in the sample, and the concentration was $361 \mathrm{ppm}$ considerably in excess of concentrations to be toxic to D. magna. Toxicity of manipulated sample relevant to $\mathrm{pH}$-change was reduced relative to untreated leachate, reinforcing our suspicion that the toxicant was ammonia. In another case of treatability-based TIE, Stronkhorst et al. indicated that tests using graduated $\mathrm{pH}$ manipulations showed significant increase in toxicity from low $\mathrm{pH}$ to high $\mathrm{pH}$ in a sediment samples in silty marine harbor dominated by ammonia or sulfide [8].

3.3. Analysis of Ammonia Toxicity. In terms of the influence of $\mathrm{pH}$ conditions on the proportion of ammonium ions to total toxicity of ammonia, it was necessary to perform 
TABLE 2: Contribution of ammonia and bisphenol A toxicity in the total toxicity of landfill leachate.

\begin{tabular}{cccccccccc}
\hline \multirow{2}{*}{ Landfill leachate } & \multirow{2}{*}{$\mathrm{pH}$} & \multicolumn{3}{c}{ Daphnia magna, $\mathrm{LC50}(\mathrm{ppm})$} & \multicolumn{3}{c}{ Contribution rate (vol\%) } \\
& & $\mathrm{NH}_{4}{ }^{+}$ & $\mathrm{NH}_{3}(\mathrm{aq})$ & Total ammonia & $\mathrm{NH}_{4}{ }^{+}$ & $\mathrm{NH}_{3}(\mathrm{aq})$ & Total ammonia & Bisphenol A Bisphenol A and ammonia \\
\hline 2008 & $8.3( \pm 0.3)$ & 19.3 & 1.64 & 20.9 & 8.7 & 50 & 58.7 & 8.21 & 66.9 \\
2009 & $7.5( \pm 0.1)$ & 110 & 2.35 & 112 & 49.5 & 71.1 & 121 & 29.0 & 150 \\
\hline
\end{tabular}

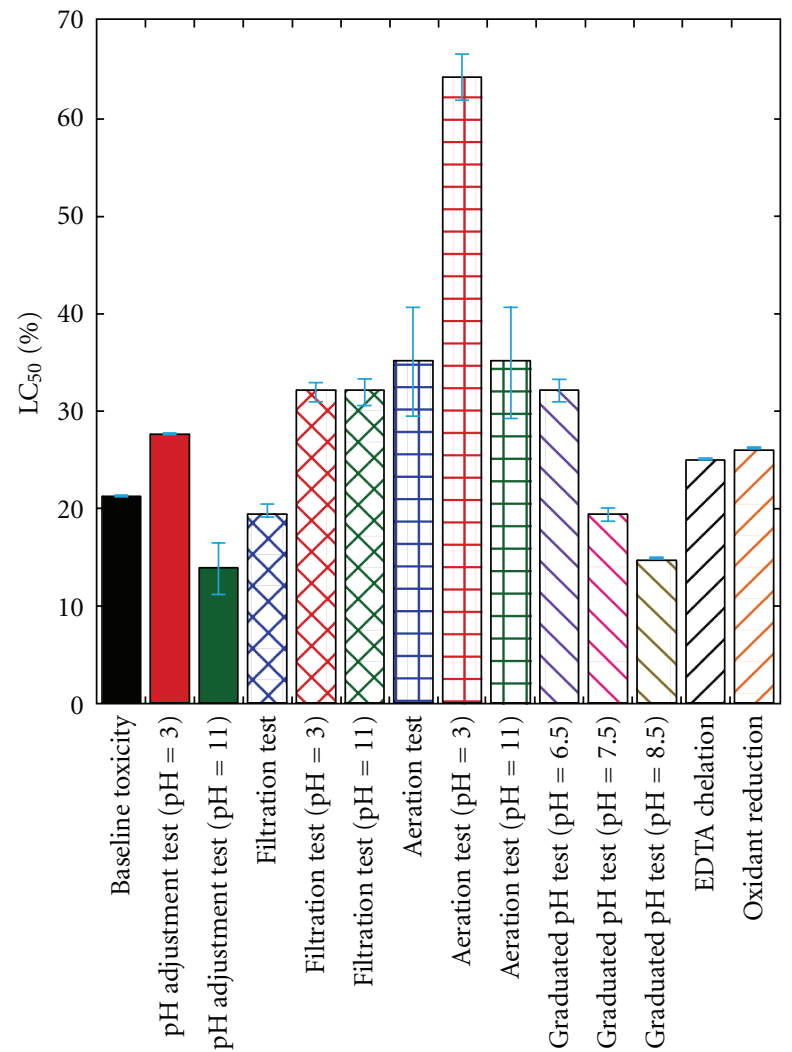

FIGURE 1: Results of acute phase I characterization testing and supplemental characterization studies Daphnia magna.

the toxicity tests with $D$. magna at defined $\mathrm{pH}$ in order to elucidate the toxicity of ammonia. Examples of concentration/response curves obtained in terms of ammonium chloride at pH 7.0 and 8.0 are shown in Figure 2. Un-ionized ammonia constituted the major source of toxicity in these investigations, even though volume of un-ionized ammonia comprised a small fraction of total ammonia, in term of a mixture of two toxic components at different proportions assuming additive effects of the two forms.

The specific toxicity of un-ionized ammonia and ammonium ion were calculated from a plot of the inverse of $\mathrm{LC}_{50}$ versus the degree of dissociation $\left(\mathrm{Ka} / \mathrm{Ka}+\mathrm{C}_{\mathrm{H}^{+}}\right)$according to (3) as shown in Figure 3. The toxicity of ammonia and ammonium ion mixture increased upon increasing $\mathrm{pH}$. From a linear fit with data of the toxic effect as $1 / \mathrm{LC}_{50 \text {,tot }}$ against dissociation expressed as dissociation of ammonium, the correlation coefficient $\left(\mathrm{R}^{2}\right)$ between observed plots and the linear function expressed as (1) was 0.93 . The toxicity of the un-ionized ammonia is obtained from the intercept, and

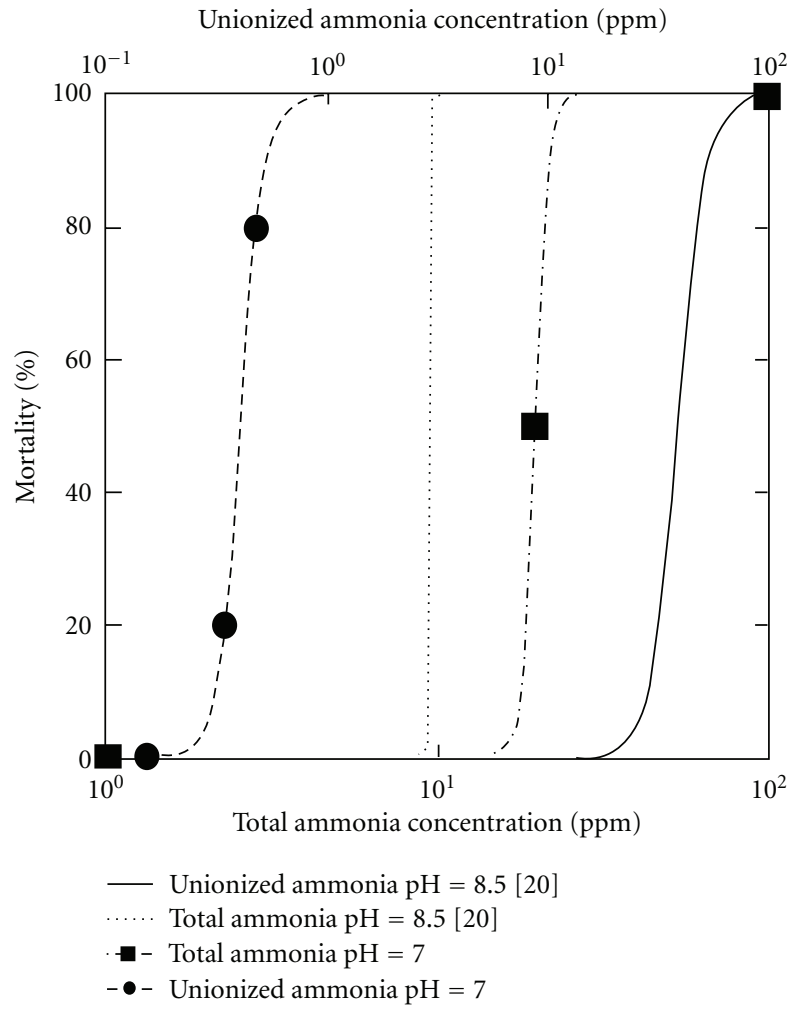

FIGURE 2: Effect of ammonia on the mortality rate of Daphnia magna at $\mathrm{pH} 7.0$ and 8.5 [20]. Concentration expressed as total ammonia or as un-ionized ammonia calculated by MINEQL+.

the toxicity of the ammonium ions from the slope and the intercept. The un-ionised ammonia toxicity $\left(\mathrm{LC}_{50, \mathrm{NH}_{3}(\mathrm{aq})}\right)$ was calculated as $3.3 \mathrm{ppm}$ and the toxicity of ammonium ions $\left(\mathrm{LC}_{50, \mathrm{NH}_{4}}{ }^{+}\right.$) was calculated as $222 \mathrm{ppm}$, that is, almost a factor 50 difference between $\left(\mathrm{LC}_{50, \mathrm{NH}_{3}(\mathrm{aq})}\right)$ and $\left(\mathrm{LC}_{50, \mathrm{NH}_{4}{ }^{+}}\right)$. Joint toxicity with these components have been observed by an algae Nephroselmis pyriformis, within almost a factor 100 difference between $\left(\mathrm{LC}_{50, \mathrm{NH}_{3}(\mathrm{aq})}\right)$ and $\left(\mathrm{LC}_{50, \mathrm{NH}_{4}}{ }^{+}\right.$. Ammonium ion is slightly toxic among different species of ammonia, but concentration of ammonium ion was much more larger than that of un-ionized ammonia around $\mathrm{pH}$ 7. The contribution of ammonium ions in the total ammonia toxicity was therefore not negligible. According to some previous studies on mixture toxicity of chemicals [9], the multiple toxicity caused by two or more chemicals can be classified into three types, additive, synergistic, and antagonistic effects. The multiple toxicity of ammonia and ammonium ion can be assumed as an additive effect [10]. As discussed above, various chemicals other than ammonia 


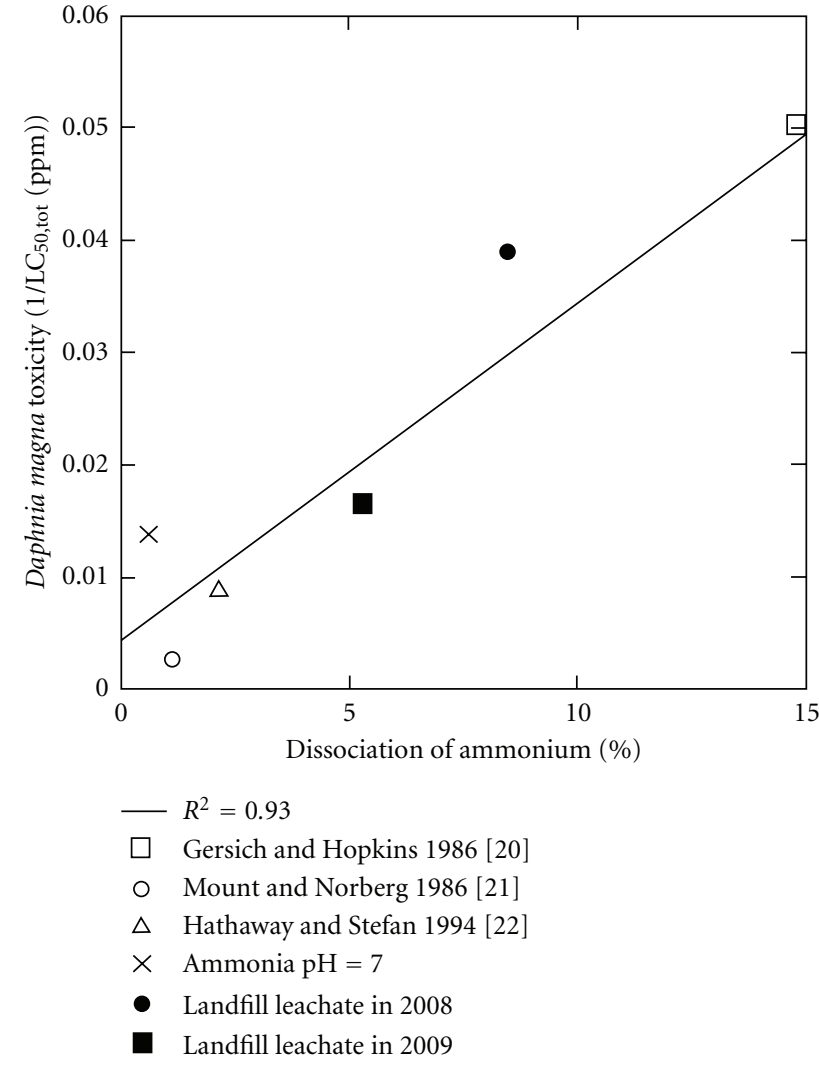

Figure 3: Ammonia toxicity in tests with Daphnia magna at different $\mathrm{pH}$ related to percentage of dissociation of ammonia [20-22].

are contained in landfill leachate. Information on multiple toxicity are too limited to discuss more on interaction among other heavy metals on organic chemicals such as bisphenol A.

3.4. TIE Based on Contribution Rate Approach. The contribution of each component in the landfill leachate toxicity were calculated according to (3), (4), and specific ammonia toxicity, and the results are presented in Table 2. Table 2 also indicates that ammonia is a main toxic constituent in the landfill leachate. Treatability-based TIE led the fact that toxicity causative chemical is only ammonia. In landfill leachate in 2008, contribution rate of ammonia toxicity was calculated as $58.7 \mathrm{vol} \%$. Contribution of other toxicity causative chemicals should be masked by the ammonia toxicity. The toxicity contribution of chemicals other than ammonia was calculated as $41.3 \mathrm{vol} \%$. In landfill leachate in 2009 , the sum of contribution rate and the lack of correlation to concentration does not allow a precise evaluation, because other components may interfere with the toxic action of ammonia. Previous papers suggest that ammonia toxicity to amphipod and fish was strongly dependent on the ionic composition of the medium (e.g., potassium and sodium ion) $[11-13]$.

As a toxicity causative chemical other than ammonia, bisphenol A (BPA) was suggested by chemical-specific TIE based on the concentration shown in Table 2. Table 2 shows the contribution of BPA toxicity in the total toxicity of landfill leachate. Contribution rate of BPA toxicity was calculated as $8.21 \mathrm{vol} \%$ in landfill leachate in the year of $2008,29.0 \mathrm{vol} \%$ in landfill leachte in the year of 2009. Although BPA was one of the toxicity causative chemicals in the landfill leachate, BPA toxicity was not determined by the SPE manipulation tests of treatability-based TIE, because toxicity of ammonia was relatively large so that the toxicity of BPA was shadowed. According to the previous studies on the toxicity of BPA, the acute toxicity data showed that BPA was moderately toxic to the invertebrates tests [14]. Shoji et al. tried to find toxicitycontrolling chemicals in waste landfill leachate [7] and waste samples such as various sludges [15]. According to their findings, BPA was found as possible candidates for toxicitycontrolling chemicals in landfill leachate and parts of waste sludge samples, respectively. In addition, the contribution of ammonia to landfill leachate toxicity was already examined in a previous study. Un-ionized ammonia was a more toxic form of ammonia and seemed to be the major toxicant for most leachates from 16 landfill sites [1].

\section{Conclusions}

A methodology to decide toxicity causative chemicals in landfill leachate based on the toxicity contribution rate and the effect of ammonia toxicity changing by $\mathrm{pH}$ was developed in this study. The contribution of ammonia toxicity in the landfill leachate toxicity was calculated as $58.7 \mathrm{vol} \%$ of the total toxicity of the landfill leachate. Other toxicity causative chemicals masked by ammonia's toxicity were detected. Contribution rate of the toxicity causative chemicals masked by ammonia toxicity was $41.3 \mathrm{vol} \%$ of the total toxicity of the landfill leachate. Bisphenol A was one of the toxicity causative chemicals other than ammonia in this study. TIE based on contribution rate approach developed in this study enables us to detect toxicity causative chemicals masked by high contribution chemicals independently of $\mathrm{pH}$ of landfill leachate.

\section{References}

[1] B. Clément and G. Merlin, "The contribution of ammonia and alkalinity to landfill leachate toxicity to duckweed," Science of the Total Environment, vol. 170, no. 1-2, pp. 71-79, 1995.

[2] USEPA, "Methods for aquatic toxicity identification evaluations, phase I: toxicity characterization procedures," EPA/ 600/6-91-003, U.S. Environmental Protection Agency, Washington, DC, USA, 1991.

[3] P. G. C. Campbell, "Interactions between trace metals and aquatic organisms: a critique of the free-ion activity model," in Metal Speciation and Bioavailabibility in Aquatic Systems, A. Tessier and D. R. Turner, Eds., pp. 44-102, Wiley, Chichester, UK, 1995.

[4] A. C. Karel, D. E. Schamphelaere, and C. R. Jansenn, "Effects of dissolve organic carbon concentration and source, $\mathrm{pH}$, and water hardness on chronic toxicity of copper to Daphnia magna," Environmental Toxicology and Chemistry, vol. 23, no. 5, pp. 1115-1122, 2004.

[5] S. S. Seefeldt, J. E. Jenson, and E. P. Fuerst, "Log-logistic analysis of herbicide dose response relationships," Weed Technology, vol. 9, no. 2, pp. 218-225, 1995. 
[6] A. Svenson and L. Zhang, "Acute aquatic toxicity of protolyzing substances studied as the microtox effect," Ecotoxicology and Environmental Safety, vol. 30, no. 3, pp. 283-288, 1994.

[7] R. Shoji, Y. Sakai, A. Sakoda et al., "Bioassay-based investigation of toxicity-controlling chemicals in waste landfill leachate," Journal of Japan on Water Environmental, vol. 26, no. 10, pp. 643-648, 2003.

[8] J. Stronkhorst, M. E. Schot, M. C. Dubbeldam, and K. T. Ho, "A toxicity identification evaluation of silty marine harbor sediments to characterize persistent and non-persistent constituents," Marine Pollution Bulletin, vol. 46, no. 1, pp. 5664, 2003.

[9] R. Shoji, A. Sakoda, Y. Sakai, H. Utsumi, and M. Suzuki, "Quantitative description of mixture toxicity of chemicals and environmental waters detected bioassay," Journal of Japan on Water Environmental, vol. 23, no. 8, pp. 487-494, 2000.

[10] T. Källqvista and A. Svenson, "Assessment of ammonia toxicity in tests with the microalga, Nephroselmis pyriformis, Chlorophyta," Water Research, vol. 37, no. 3, pp. 477-484, 2003.

[11] U. Borgmann and A. I. Borgmann, "Control of ammonia toxicity to Hyalella azteca by sodium, potassium and $\mathrm{pH}$," Environmental Pollution, vol. 95, no. 3, pp. 325-331, 1996.

[12] D. J. Randall and T. K. N. Tsui, "Ammonia toxicity in fish," Marine Pollution Bulletin, vol. 45, no. 1-12, pp. 17-23, 2002.

[13] N. Romano and C. Zeng, "Acute toxicity of ammonia and its effects on the haemolymph osmolality, ammonia- $\mathrm{N}, \mathrm{pH}$ and ionic composition of early juvenile mud crabs, Scylla serrata (Forskål)," Comparative Biochemistry and Physiology Part A, vol. 148, no. 2, pp. 278-285, 2007.

[14] H. C. Alexander, D. C. Dill, L. W. Smith, P. D. Guiney, and P. B. Dorn, "Bisphenol A: acute aquatic toxicity," Environmental Toxicology and Chemistry, vol. 7, no. 1, pp. 19-26, 1988.

[15] R. Shoji, S. Mohri, Y. Sakai, and M. Yamada, "Ecotoxicity assessment of sludge and leaching test eluates of sludge," Journal of Environmental Science and Health Part A, vol. 43, no. 9, pp. 1-6, 2008.

[16] B. F. Dowden and H. J. Bennett, "Toxicity of selected chemicals to certain animals," Water Pollution Control Federation, vol. 37, no. 9, pp. 1308-1316, 1965.

[17] R. B. Naddy, W. A. Stubblefield, J. R. May, S. A. Tucker, and J. R. Hockett, "The effect of calcium and magnesium ratios on the toxicity of copper to five aquatic species in freshwater," Environmental Toxicology and Chemistry, vol. 21, no. 2, pp. 347-352, 2002.

[18] G. A. Chapman, S. Ota, and F. Recht, "Effects of water hardness on the toxicity of metals to Daphnia magna," Tech. Rep., U.S. EPA, Corvallis, Ore, USA, 1980.

[19] M. Erten-Unal, B. G. Wixson, N. Gale, and J. L. Pitt, "Evaluation of toxicity, bioavailability and speciation of lead, zinc and cadmium in mine/mill wastewaters," Chemical Speciation and Bioavailability, vol. 10, no. 2, pp. 37-46, 1998.

[20] F. M. Gersich and D. L. Hopkins, "Site-specific acute and chronic toxicity of ammonia to Daphnia magna straus," Environmental Toxicology and Chemistry, vol. 5, no. 5, pp. 443-447, 1986.

[21] D. I. Mount and T. J. Norberg, "Seven-day life-cycle cladoceran toxicity test," Environmental Toxicology and Chemistry, vol. 3, no. 3, pp. 831-840, 1986.

[22] C. J. Hathaway and H. G. Stefan, "Model of Daphnia populations for wastewater stabilization ponds," Water Research, vol. 29, no. 1, pp. 195-208, 1994. 

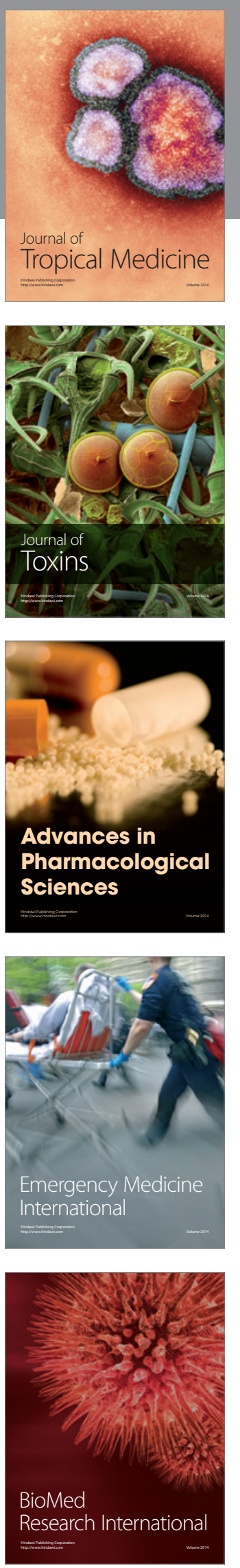
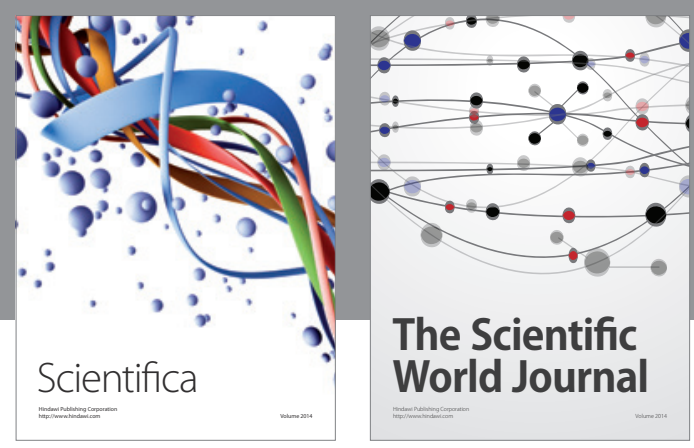

The Scientific World Journal
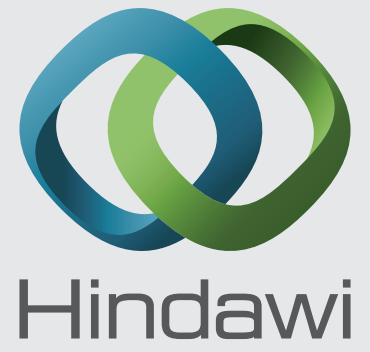

Submit your manuscripts at

http://www.hindawi.com
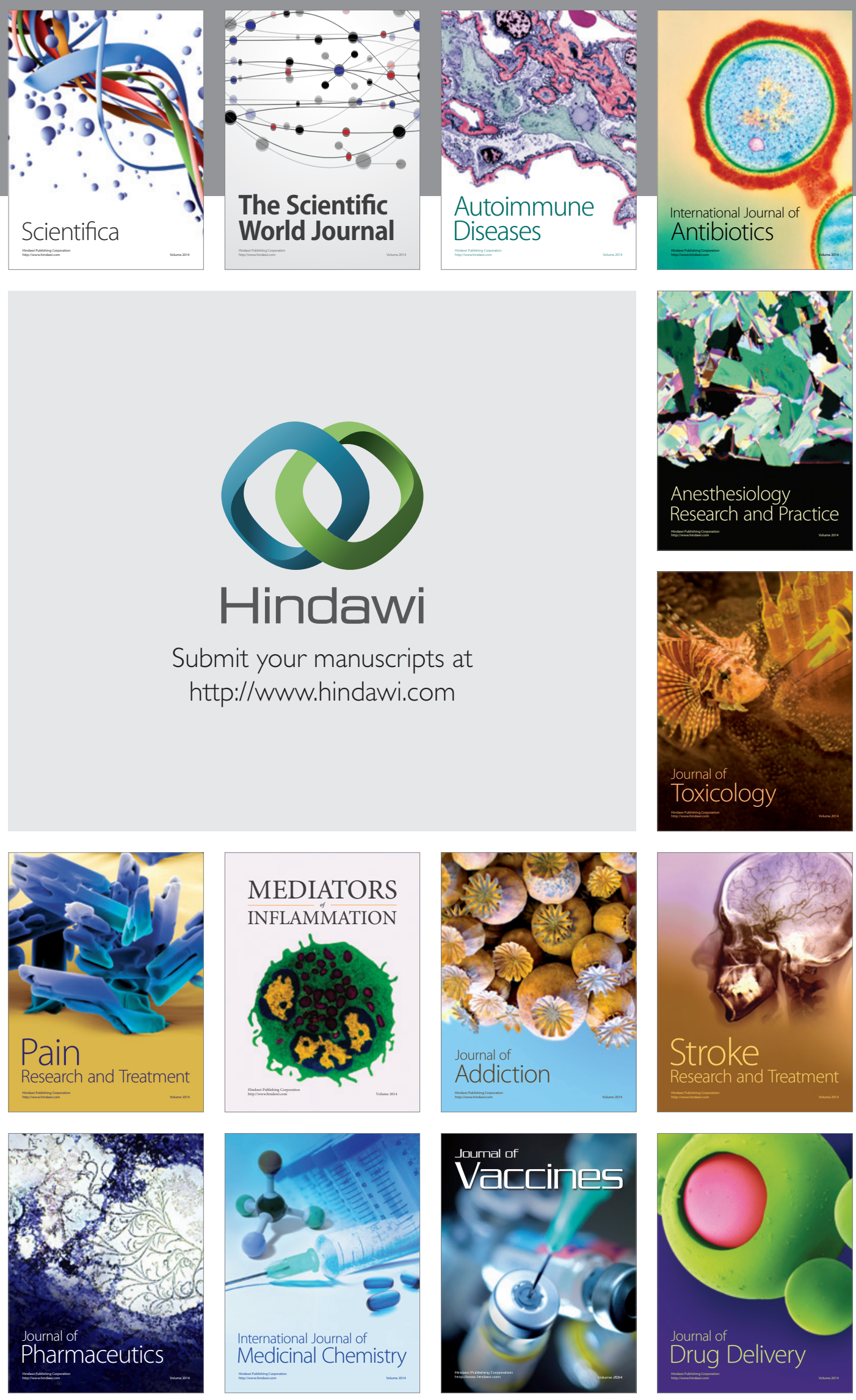